\title{
O sonho de Julius e Ethel Rosenberg: Antissemitismo, opinião pública e a U.S. information agency
}

\author{
The dream of Julius and Ethel Rosenberg: \\ Anti-semitism, public opinion and the U.S. information agency
}

Júlio Barnez Pignata Cattai*

Resumo: No presente artigo, analisamos a atuação, no início dos anos 1950, da agência de informação e propaganda do governo dos EUA, a United States Information Agency, em relação ao processo movido na justiça do país contra o casal de judeus Julius e Ethel Rosenberg, acusados de espionagem em favor da União Soviética. Especificamente, analisamos a atuação de tal agência em dois importantes jornais brasileiros do período, o "Correio da Manhã" e a "Tribuna da Imprensa". Mais do que discutir a singularidade do processo do casal Rosenberg, nosso objetivo é chamar atenção o fato de que, para além dos campos já conhecidos e consideravelmente explorados pela historiografia sobre a Guerra Fria, havia outro campo importante de disputa no período: o da propaganda cultural - no que a historiografia, notadamente estadunidense, tem chamado de "Cultural Cold War".

Palavras-chaves: Antissemitismo - Cultural Cold War - United States Information Agency. *Mestre e doutorando em História Social pela Universidade de São Paulo, São Paulo/SP,
Brasil. E-mail: juliocattai@gmail.com

(cc) EY Direito autoral e licença de uso: Este artigo está licenciado sob uma Licença Creative Commons. Com essa licença você pode compartilhar, adaptar, para qualquer fim, desde que atribua a autoria da obra, forneça um link para a licença, e indicar se foram feitas alterações. 


\begin{abstract}
In this article, we analyze the performance, in early 1950's, of the United States Information Agency in relation to the case brought in to the justice of the country against the Jewish couple Julius and Ethel Rosenberg, accused of espionage in favor of the Soviet Union. Specifically, we analyze the performance of such agency in two major Brazilian newspapers of the period, "Correio da Manhã" and "Tribuna da Imprensa". More than discussing the uniqueness of the couple Rosenberg process, we aim to call attention to the fact that, in addition to the fields already known and greatly exploited by the historiography of the Cold War, there was another important field of dispute during the period: the cultural propaganda, which the historiography especially in the United States has been calling the "Cultural Cold War."
\end{abstract}

Keywords: Antisemitism - Cultural Cold War - United States Information Agency.

\footnotetext{
- Ninguém acredita nas infâmias que estão publicando contra você - disse Gertrude, abaixando muito a voz, como se os dois homens que estavam ali pudessem não ouvir. Todas as pessoas decentes estão indignadas ao ver o governo usar essas calúnias para enfraquecer o manifesto a seu favor que tanta gente importante assinou, Roger. ${ }^{1}$
}

Sir Roger Casement estava preso na Inglaterra, após sua captura na Irlanda, pelas forças britânicas, em meados dos anos 1910, acusado de alta traição e espionagem contra o governo britânico. O título de nobreza, que então perderia, ganhara dos ingleses como reconhecimento de trabalhos realizados no Congo belga e na região do rio Putumayo, na Amazônia peruana: relatórios produzidos nos muitos anos que passou naquelas regiões dando conta dos abusos das empresas que se dirigiam a elas sob o signo da civilização e de Deus. Seus detalhados relatórios para o Foreign Office chocaram as opiniões públicas europeia e estadunidense, que passaram a exercer pressão sobre o império belga por mudanças em relação ao "intento civilizatório" do rei Leopoldo II na África e sobre a Companhia inglesa de exploração de borracha, de Júlio César Arana, no Peru. Casement tornara-se, assim, um célebre intelectual do Império. No entanto, sua participação, na Irlanda, em abril de 1916, no Levante da Semana Santa, movimento que lutava pela independência do país do jugo britânico, faria mudar sensivelmente a opinião que se tinha de Roger.

A desconstrução da imagem do irlandês - que, em sentido contrário, conseguiu o apoio de uma porção de intelectuais, entre eles George Bernard Shaw, pela comutação de sua pena - junto à opinião pública pelo governo britânico passou, então, pela circulação de alguns de seus diários pessoais, os chamados "Black Diaries", que traziam relatos obscenos de sua vida 
sexual, o que serviu de justificativa, na época, para sua insanidade mental. Destacados nas fotografias dos diários, distribuídas para figuras-chave que apoiavam o movimento de clemência em favor de Roger: o homossexualismo, a perversão sexual e seu envolvimento com crianças. $\mathrm{O}$ efeito de tais diários, cuja autenticidade ainda não se pôde comprovar com segurança ${ }^{2}$, sobre a opinião pública, tanto na Irlanda como na Inglaterra, foi devastadora para a imagem de Casement. Após sua execução, em 1917, a memória de Roger Casement foi esquecida, silenciada, até que, muitos anos depois, em 1965, o governo da Irlanda, já independente, conseguiu do governo da Inglaterra que os restos mortais do Celta voltassem à sua terra natal, onde foram recebidos como os de um herói. ${ }^{3}$

A história em que se envolveu o casal Julius e Ethel Rosenberg, no início da década de 1950, também preso sob a acusação de alta traição e espionagem, tem semelhança com o que se passou com Roger Casement, mais particularmente no que concerne à mobilização da opinião pública em torno de sua imagem e processo. Tal como Casement, que sonhava a independência da Irlanda, os Rosenberg sonhavam a vitória da União Soviética (URSS) e da revolução comunista na Guerra Fria. A diferença, no entanto, é que, no após Segunda Guerra, vivia-se o embate de Guerra Fria, quando a influência sobre a opinião pública ${ }^{4}$ tornara-se, também, campo privilegiado de disputa entre a Casa Branca e o Kremlin - o que deles demandou a fundação de serviços especializados de atuação em tal campo - no granjeamento de governos às suas respectivas posições no cenário internacional.

Nos Estados Unidos da América (EUA), em meados do século XX, os casos de espiões soviéticos infiltrados em órgãos estratégicos do país, como o Projeto Manhattan, em Los Alamos, de desenvolvimento da bomba atômica, já não eram novidade. De um modo geral, tais casos chegavam a público no país e, da mesma maneira espetacular que alcançavam os meios de comunicação, desapareciam sem grande alarde. O caso dos chamados "espiões atômicos", Julius e Ethel Rosenberg, no início dos anos 1950, no entanto, alcançou uma projeção mundial sem precedentes e que não se viu repetir nos anos de Guerra Fria.

Ao processo, subjazia o revival de políticas antissemitas pelo Kremlin, por essa época, o que causara críticas severas ao Bloco pela opinião pública europeia. Como efeito, o governo soviético lançou uma campanha mundial pelo perdão aos judeus Rosenberg: atravessava o argumento pela clemência, a ideia de que nos EUA havia uma política antissemita velada, contraditória à expressão projetada pelo mundo de o país ser uma democracia liberal. Ademais, Julius Rosenberg parecia, ao Departamento de Justiça, uma das peças-chave da rede de espionagem que se articulara nos órgãos de governo nos Estados Unidos, o que tornava ainda maior o interesse em torno do casal. Os Rosenberg viramse, então, lançados para o centro de uma disputa entre os governos soviético e 
estadunidense pela interpretação que a opinião pública mundial deveria fazer do significado de seu processo.

No presente artigo, discutimos de que maneira a agência fundada, em 1953, pela administração de Dwight D. Eisenhower, a U. S. Information Agency (USIA), responsável por uma sofisticada atuação junto à opinião pública estrangeira no sentido de aproximá-la dos valores positivos da vida nos Estados Unidos, tratou o caso dos "espiões atômicos" em dois dos mais importantes jornais brasileiros do período, o "Correio da Manhã" e a "Tribuna da Imprensa". ${ }^{6}$ Discutimos, para tanto, como o ocaso dos judeus na União Soviética pela época do julgamento do casal e a importância atribuída a Julius foram decisivos para que eles despontassem como tema relevante, tanto para o Kremlin como para a Casa Branca, no embate pela opinião pública mundial.

Julius e Ethel Rosenberg, condenados à morte, depois de um processo que durou vinte meses, no qual foram ambos acusados de passar segredos atômicos dos Estados Unidos para a União Soviética, esgotaram seus recursos, segundo o direito norte-americano, para buscar possível reconsideração do caso. (...) No período de dois anos e quatro meses, desde que foram presos, em 1950, o casal acusado usou os direitos conferidos pela lei, conseguindo três julgamentos separados e quatro apelações. A União Americana de Liberdades Civis anunciou publicamente que a sentença de morte imposta aos Rosenberg não constitui violação de liberdade civil. (...) a União declarou recentemente não ter encontrado provas de que a sentença foi lavrada por motivos políticos ou religiosos. (...) Os crimes pelos quais os acusados respondem começaram em 1944, quando David Greenglass, irmão da sra. Rosenberg, então oficial do exército, foi designado para instalações altamente secretas do governo. Ele não sabia tratar-se de um centro de trabalho para a bomba atômica. Mas sua irmã e seu cunhado, já figuras de destaque numa conspiração para roubar segredos atômicos dos Estados Unidos para a União Soviética, o sabiam e não perderam tempo em tirar vantagem da nomeação de Greenglass. Este, maquinista na vida civil, foi persuadido a entregar aos Rosenberg desenhos e outros materiais descritivos que conseguia em seu trabalho, em Los Alamos, no Novo México. Disseramthe que o material era para ser entregue aos russos. O grupo de espionagem ligada a Rosenberg, em Nova York, recebeu informações de Greenglass em 1944 e em várias ocasiões, em 1945. Trabalhavam ainda por outros meios para conseguir informações destinadas aos agentes secretos da União Soviética. Julius Rosenberg foi preso em julho 
de 1950; Ethel, sua esposa, em agosto do mesmo ano. (...) A leitura de seu processo não deixa dúvida de que a condenação se baseou exclusivamente em fatos. ${ }^{7}$

Virara o ano de 1952 para 1953 e os funcionários do United States Information Service (USIS) ${ }^{8}$, no Brasil, conseguiram que o matutino carioca, o jornal "Correio da Manhã", publicasse uma extensa matéria entregue por eles acerca do processo movido na justiça dos EUA contra os "espiões atômicos", acusados de repassar segredos da bomba atômica estadunidense aos soviéticos. Publicada na primeira página do segundo caderno do jornal, a matéria intitulada "O processo dos Espiões Rosenberg" fazia um histórico do caso, ressaltando a legalidade do julgamento que condenara o casal à pena capital.

$\mathrm{O}$ histórico, com destaque à legitimidade do julgamento, tinha seu motivo de ser: a USIA e o Conselho de Segurança Nacional (NSC) ${ }^{9}$ nos EUA estavam atentos à atuação dos programas de propaganda cultural do governo soviético em relação ao caso dos "espiões atômicos". Tal como se dera no processo movido, no início dos anos 1920, contra os anarquistas italianos Nicola Sacco e Bartolomeu Vanzetti, acusados e, posteriormente, executados pelo homicídio de um contador e de um guarda de uma fábrica de sapatos nos Estados Unidos, no caso dos Rosenberg as opiniões públicas no estrangeiro vinham sendo mobilizadas, em parte, pela propaganda cultural organizada pelo Kremlin. ${ }^{10}$

O enfoque de tal propaganda era a organização de uma grande campanha de clemência ao casal: nos jornais ligados ao governo soviético, ou a ele alinhados, fazia-se um apelo dramático pela vida dos acusados, ao mesmo tempo em que um grande número de petições, nesse mesmo sentido, eram enviadas às embaixadas estadunidenses espalhadas pelo mundo, em particular às de Paris e Londres e à de Ottawa, onde se armou um piquete permanente em favor de Julius e Ethel. A campanha, numa articulação comum à agenda dos programas de propaganda cultural de ambas as superpotências ${ }^{11}$, pôde fazer projeção de seu discurso por meio da produção de artístas e intelectuais, como Pablo Picasso, em pinturas, fotografias, poemas, ensaios e cartas, em defesa do casal. ${ }^{12} \mathrm{O}$ intuito do governo da União Soviética, segundo o Secretário de Estado dos EUA, John Foster Dulles, era que fosse gerada, nas audiências internacionais, uma simpatia pelos acusados que, por fim, levantasse dúvidas sobre o veredito do processo e sobre a aplicação democrática da lei nos Estados Unidos. ${ }^{13}$ A avaliação de Dulles era correta, embora parcialmente, como veremos.

Não era a primeira vez que chegava ao público internacional a evidência de que o governo soviético possuía agentes infiltrados nos serviços de inteligência e de desenvolvimento da bomba atômica de governos ocidentais. Em setembro de 1945, para citar um dos primeiros e mais impressionantes 
casos de espionagem revelado ao público, Igor Gouzenko abandonou seu posto como criptógrafo da embaixada soviética em Ottawa com uma porção de documentos secretos escondidos sob a camisa e alguns nomes para apontar como agentes soviéticos infiltrados nos governos do Canadá, dos Estados Unidos e da Inglaterra. ${ }^{14}$ Entretanto, o processo contra Julius e Ethel Rosenberg ganhou uma projeção sem precedentes em todo o mundo. Em parte, como vimos, pelas mãos dos programas de propaganda cultural do Kremlin, mas também pelas da USIA, conforme matéria citada, que vinha veiculando o caso em jornais como o "Correio da Manhã".

Inicialmente, a prisão e o processo movido na justiça estadunidense contra Julius e Ethel Rosenberg não geraram considerável interesse entre os responsáveis pelos programas de propaganda cultural da URSS. No final do ano de 1952, porém, o Kremlin voltou-se maciçamente para o caso. Para funcionários do governo dos EUA, esse renovado interesse deu-se, sobretudo, em virtude da reação da opinião pública europeia em relação ao processo e execução do judeu Rudolf Slansky e de outros líderes comunistas (a maioria deles judeus), e as implicações antissemitas que teriam tido. ${ }^{15}$

Rudolf Slansky, um dos mais importantes membros do Partido Comunista da Tchecoslováquia (PCT), fora, em 1948, o principal articulador do coup d'état comunista no país, tornando-se Secretário-Geral do Partido e a segunda figura de maior relevo na política tcheca. Entretanto, suas posições passaram a desagradar o alto escalão do governo soviético. Em novembro de 1951, a mando de Stálin, a polícia secreta da Tchecoslováquia (Statni bezpecnost) prendeu o Secretário-Geral do PCT e outros treze líderes comunistas, dez deles judeus.

A acusação que lhes recaia era de alta traição contra o governo de Praga, espionagem para o Ocidente e sabotagem da economia socialista. Em novembro de 1952, diante do tribunal, os implicados nos referidos crimes confessaram as acusações, descrevendo suas vidas como motivadas pelo ódio ao PCT, lealdade à Gestapo - a polícia da Alemanha Nazista -, ao sionismo, aos serviços de inteligência ocidentais e ao capital internacional. Todos exigiram do juiz responsável pelo processo que lhes impusesse a pena de morte. ${ }^{16}$

Em dezembro daquele ano, Slansky e outros dez acusados foram executados. Segundo o historiador Igor Lukes, no trabalho em que analisa o processo contra o Secretário-Geral do Partido Comunista da Tchecoslováquia, o caso Slansky ocorrera no período imediatamente posterior à separação da Yugoslávia, do Marechal Tito, da União Soviética. Os processos movidos contra líderes comunistas em Praga, na Tchecoslováquia; Varsóvia, na Polônia; Budapeste, na Hungria; e em outras capitais do leste europeu eram uma mensagem do Kremlin aos governos da "cortina de ferro" de que apenas aceitaria lideranças obedientes às suas diretrizes. Dos catorze acusados no processo de Praga, entretanto, somente os onze judeus foram executados, sendo 
os demais condenados à prisão perpétua. Stálin escolhera primariamente os judeus porque ele reorientava sua estratégia de alianças em relação ao Oriente Médio, aproximando-se dos países Árabes e distanciando-se de Israel. ${ }^{17}$ Todavia, havia mais elementos em torno do processo de Praga.

Pouco depois da execução de Slansky, apareceu na mídia internacional, o caso do "Complô dos Médicos", veiculado pela agência de notícia da União Soviética, TASS, a partir de 13 de janeiro de 1953. O caso iniciara-se com a morte, por insuficiência cardíaca, em agosto de 1948, de uma das figuraschave do regime soviético, Andrei Zhdanov: à morte seguiu-se uma disputa, entre os médicos que o haviam tratado, sobre as verdadeiras causas do óbito, com acusações de negligência entre eles. O "Complô dos Médicos", em 1953, quando foram presos nove médicos na União Soviética, a maioria judeus, aparecia a partir da "revelação" de que Zhdanov fora assassinado por seus médicos como o ponto de partida de um audacioso plano conspiratório judaico para derrubar a União Soviética.

Em 14 de janeiro de 1953, um dia após as revelações da TASS, o jornal carioca "Tribuna da Imprensa" publicou, em sua segunda página, sob o título em destaque "Declaração de Guerra: como os judeus receberam o comunicado russo", uma notícia sobre o "Complô":

Os judeus receberam como declaração de guerra o comunicado de Moscou sobre a prisão de 9 médicos, quase todos judeus, acusados de terrorismo.

Nenhum comunicado oficial até o momento. O cidadão comum, entretanto, sente que já não há nenhuma diferente entre o anti-semitismo nazista e comunista.

O Departamento de Estado distribuiu comunicado oficial, que diz: - A prisão de médicos judeus, acusados de sabotagem, parece uma nova etapa da recente campanha russa contra os judeus, como o aspecto anti-sionista levado no julgamento dos acusados. Os soviéticos recorrem de novo a uma velha técnica. Os motivos verdadeiros das atuais acusações ainda não são conhecidos mas a técnica da sabotagem já foi empregada no processo "expurgo" de 1937. Tonar-se cada vez mais evidente que tais alegações (complots sionistas) indicam um desenvolvimento extraordinário do "sentimento de insegurança interna" entre dirigentes russos. ${ }^{18}$

O governo dos Estados Unidos, conforme correspondência do Secretário de Estado John Foster Dulles para o embaixador na URSS, Charles Bohlen, embora jogando com hipóteses, compreendia que o caso com os médicos judeus era uma tentativa de aumentar a vigilância à população soviética no interior do Bloco ou refletia um problema político no círculo superior de poder em torno 
de Stálin. A administração Eisenhower acreditava, além disso, que o "Complô" era um factóide criado por Stálin para proceder a uma nova política de expurgo, tal como se dera nos anos 1930, em relação aos judeus. ${ }^{19}$

A esse respeito, Hannah Arendt, em seu "Origens do Totalitarismo", aproximando as políticas de Stálin e Hitler, considera que:

Tudo o que se sucedeu na Rússia entre 1948 e janeiro de 1953, quando a "conspiração dos médicos" estava sendo "descoberta", tinha uma notável e ominosa semelhança com os preparos do Grande Expurgo dos anos 1930: a morte de Zhdanov e o expurgo de Leningrado correspondiam à não menos misteriosa morte de Kirov em 1934, que foi imediatamente seguida de uma espécie de expurgo preparatório "de todos os antigos opositores que ainda existiam no Partido". Além do mais, o próprio conteúdo da absurda acusação contra os médicos - que iriam matar pessoas em posição de destaque em todo o país - deve ter enchido de temerosos presságios todos os que conheciam o método de Stálin, de acusar um inimigo fictício de um crime que ele mesmo ia cometer. ${ }^{20}$

Nos novos expurgos de Stálin, sob a justificativa de uma "conspiração mundial judaica" - o que, para Arendt, não era efeito de episódios isolados, mas a instituição mesma do terror de que os regimes totalitários lançavam mão de tempos em tempos -, o processo de Slansky e de outros líderes comunistas do Bloco, ainda conforme a pensadora, constituíam-se numa preparação para expurgos de alcance nacional, para cujo cumprimento o "Complô dos Médicos" seria o ponto de partida. ${ }^{21}$

Stálin, na segunda metade dos anos 1940, iniciara o rebaixamento, demissão ou execução de judeus da máquina do Estado, principalmente de uma intelectualidade - conhecida como "cosmopolita", de origem judaica, em grande medida - que teria ligações com o ocidente. O líder da União Soviética talvez estivesse receoso do significado das demonstrações populares de apoio à criação do Estado de Israel, em maio de 1948, pelo primeiro-ministro Ben Gurion, o que era evidente, por exemplo, com as homenagens prestadas pelos judeus soviéticos à primeira embaixadora israelense, Golda Meir, na URSS. ${ }^{22}$ Além disso e da preocupação com o alinhamento dos líderes comunistas dos países do Bloco Soviético, Stálin, possivelmente, também estava atento à manutenção de sua liderança no interior do Kremlin. ${ }^{23}$

É pouco provável que, no âmbito de tais acontecimentos na URSS, os serviços de informação e propaganda do governo dos EUA, ademais partícipes da composição da política externa do país, não soubessem do conteúdo antissemita que passara a permear a política soviética. O material veiculado 
pelos funcionários do USIS no Brasil e publicado pelo "Correio da Manhã" aponta para essa compreensão, como é o caso das duas notícias a seguir, de fevereiro e janeiro de 1953, respectivamente:

A Junta Executiva do Congresso das Organizações Industriais consita (sic) aos povos livres de todas as partes a que ergam suas vozes contra o ressurgimento do antisemitismo na União Soviética e países satélites. (...) A junta fala em nome de mais de seis milhões de membros dos 35 sindicatos filiados ao CIO. Eis alguns trechos da resolução. "Em meses recentes, evidências indubitáveis de antisemitismo na União soviética (sic) e nações satélites comunistas romperam a cortina de ferro. Os resultados dessa nova política soviética são tangíveis. "Em Moscou, médicos, judeus foram presos e indubitavelmente serão executados. Na Alemanha Oriental, o punhado de judeus que sobreviveram ao antisemitismo de Hitler estão fugindo do antisemitismo stalinista, para a democrática Berlim Ocidental. (...).

A Comissão de Judeus Americanos informou que a campanha anti-semita dos bolcheviques acaba de ser adotada como política oficial do Kremlin. Revelou que cerca de 600 mil judeus foram, em consequência, recolhidos aos campos de concentração da Rússia e satélites. Revela notar que na Rússia existem aproximadamente 2 milhões de israelitas. ${ }^{24}$

$\mathrm{Na}$ "Tribuna da Imprensa", no mesmo período e de maneira semelhante, em notícia sem atribuição - possivelmente entregue ao jornal por funcionários do USIS ${ }^{25}$ - e sob o título de "Campanha antissemita na cortina de ferro", também se relatava o antissemitismo do governo soviético.

Foi distribuída à Imprensa a seguinte nota: “A Confederação das Entidades Representativas da Coletividade Israelita do Brasil (...), profundamente consternada e preocupada com as levianas quão tendenciosas insinuações de índole anti-semita, levantadas contra os judeus e o judaísmo em geral e, precipitadamente, contra o movimento sionista e Midinat Israel, no Processo [de Rudolf Slansky] de Praga, assim como com as discriminações antijudaicas surgidas nas manifestações populares nos países por detrás da "cortina de ferro", vem lavrar o seu veemente protesto contra aquelas malignas e infundadas imputações (....). ${ }^{26}$ 
Diante do antissemitismo de Stálin e da repercussão mundial que tiveram casos como o de Slansky e o "Complô dos Médicos", os serviços de inteligência do governo estadunidense acreditaram ser possível criar uma cisão no interior do movimento comunista em torno da questão judaica a partir do uso da imagem que alcançara o casal de judeus, Julius e Ethel Rosenberg. Um memorando da Agência Central de Inteligência (CIA), de 22 de janeiro de 1953, parece confirmar essa hipótese. Para os funcionários da agência de inteligência,

\begin{abstract}
o casal está idealmente situado para servir como destacados instrumentos de uma campanha psicológica designada a dividir o mundo comunista em torno da questão judaica, criando grupos insatisfeitos entre os membros dos Partidos a serem utilizados em trabalhos, futuros, de infiltração e de inteligência. ${ }^{27}$
\end{abstract}

Os funcionários da CIA, de fato, prometeram a Julius e Ethel que o processo contra eles seria esquecido caso eles aceitassem “(...) apelar aos judeus em todos os países a deixarem o movimento comunista e procurassem destruí-lo." ${ }^{28} \mathrm{O}$ motivo para a atenção especial em torno dos Rosenberg era, afinal, em poucas palavras, porque eram judeus.

À contrapartida do que pretendiam a CIA, com os judeus em relação ao comunismo, e a U.S. Information Agency, projetando o antissemitismo da política soviética junto à opinião pública brasileira, por exemplo, o Kremlin vinha articulando a propaganda em torno do caso Rosenberg: o processo movido contra os judeus Julius e Ethel por órgãos oficiais estadunidenses seria uma demonstração de que havia uma política antissemita velada nos EUA - o que políticos como o democrata John Rankin, um dos articuladores do Comitê de Atividades Antiamericanas do Congresso (HUAC), pareciam confirmar com sua interpretação, por exemplo, de que o movimento pela igualdade racial no país não passava de uma conspiração judaica. ${ }^{29}$

Por isso, a questão era tão intrincada, alcançando tamanha projeção: o caso Rosenberg era palco de disputa entre a propaganda do Kremlin e a da Casa Branca em torno do antissemitismo.

Em dezembro de 1952, a administração do presidente Harry Truman discutia como reagir à vasta propaganda do governo soviético em torno dos Rosenberg; propaganda essa articulada no sentido não apenas de criar uma irrefreável campanha pela clemência do casal, mas também de evidenciar a improbidade do sistema capitalista. Uma das diretrizes tomadas então foi o fornecimento, aos postos do United States Information Service, de material relativo aos trabalhos das instituições envolvidas com o processo (a Suprema Corte, a Corte de Apelação e a União Americana de Liberdades Civis), a partir do qual os USIS organizariam a informação a ser veiculada nos serviços de comunicação estrangeiros. ${ }^{30}$ Correspondendo a essa orientação, num primeiro 
momento, as notícias dos postos USIS no Brasil, publicadas pelo "Correio da Manhã”, trabalhavam o respeito às liberdades e aos direitos civis dos acusados, apoiando-se, justamente, nos argumentos daquelas três instituições. No dia 10 de fevereiro, por exemplo, o jornal publicou uma notícia intitulada "Não houve violação das liberdades civis no caso Rosenberg":

William L. White, membro da Junta de Diretores da União das Liberdades Civis Americanas, em carta ao "New York Times" aludindo ao caso dos espiões Ethel e Julius Rosenberg, declara que não houve qualquer violação das liberdades civis no julgamento e condenação dos mesmos. Friza que a campanha bolchevique a favor desses espiões não visa os interesses dos casal Rosenberg mas única e exclusivamente os interesses e objetivos do próprio Partido Comunista. $^{31}$

Ainda naquele mês, John F. Dulles, Secretário de Estado do sucessor de Truman, Dwight D. Eisenhower, enviou aos postos diplomáticos do país uma diretriz mais específica aos trabalhos a serem realizados em torno do caso dos "espiões" Rosenberg, embora não destoasse muito da diretriz anterior. O que o motivou foi, em particular, o anúncio do Presidente, também em fevereiro de 1953, mantendo a sentença de pena capital aos "espiões atômicos", proclamada dois anos antes pelo juiz Kaufman - anúncio que seu antecessor postergara até deixar a presidência.

Em suma, Dulles indicava a necessidade de demonstrar a legitimidade da decisão do Presidente, enfatizando o ponto de que estaria calcada nos poderes conferidos ao chefe do Executivo pelas leis do direito estadunidense, de uma sociedade livre e democrática. No que concernia à questão do antissemitismo, o Secretário de Estado sublinhava que não se deveria estabelecer qualquer ligação entre os processos movidos pelo Kremlin contra os líderes comunistas (vítimas dos novos expurgos de Stálin) e o dos Rosenberg (espiões de fato). O Secretário também desejava que se deixasse clara a severidade da pena como algo proporcional à enormidade do crime, deliberado e premeditado, a partir de um princípio de comparação entre a morte do casal e os riscos à segurança do mundo produzidos por Julius e Ethel ao fornecerem os segredos da bomba atômica aos soviéticos - argumento que o juiz Kaufman vinha enfatizando. Ademais, no tratamento do caso, dever-se-ia concentrar na apresentação factual e num histórico do processo, esclarecendo que todas as revisões do caso falharam em demonstrar qualquer possibilidade de clemência aos acusados. ${ }^{32}$

Quanto a essas orientações, é interessante notar que os funcionários do USIS do Brasil, assim como agências internacionais de notícias, como a Reuters e a United Press, já vinham enfatizando o argumento do juiz Irving Kaufman em sua decisão pela pena capital aos acusados. Em notícia do United 
States Information Service, o crime cometido por Julius e Ethel fora, para o juiz Kaufman, muito pior do que o "assassínio frio e premeditado", uma vez que sua conduta já havia causado "a agressão comunista na Coréia", fazendo com que "outros milhões de inocentes" pudessem vir a "pagar o preço" de sua "traição". ${ }^{33}$

O casal, entretanto, não foi executado em fevereiro, como se previa após o posicionamento de Eisenhower sobre o processo, possivelmente porque o Departamento de Justiça queria ganhar tempo com as investigações em torno de Julius, uma vez que acreditava ser este uma das figuras-chave da espionagem soviética para obter segredos atômicos dos Estados Unidos em favor da União Soviética. ${ }^{34}$ Os seguidos adiamentos da sentença, no entanto, acabaram por suscitar a desconfiança das opiniões públicas pelo mundo em relação à validade do processo movido contra os Rosenberg. ${ }^{35}$

O Secretário de Estado, John F. Dulles, interpretava, pouco antes da execução do casal, que as dificuldades em torno do caso foram motivadas, além da própria propaganda engendrada pelo Kremlin, por uma posição desinformada e emocional da opinião pública, incluindo a de não comunistas, contra a pena de morte. Até mesmo representantes diplomáticos dos Estado Unidos - embora, aparentemente, apenas preocupados com os efeitos sobre a opinião pública mundial - apelavam para a "tradição humanista" da democracia estadunidense, opondo-se ao cumprimento da sentença. ${ }^{36}$ Posição semelhante a que, no Brasil, a Câmara dos Deputados propunha-se a adotar ao discutir a possibilidade de pedir clemência ao casal. Em 18 de junho de 1953, na página 9 de seu primeiro caderno, o jornal "Correio da Manhã" publicou uma extensa notícia dando conta do debate na Câmara em torno do processo de Julius e Ethel:

A hora do expediente, ontem, na Câmara dos Deputados, foi quase inteiramente ocupada com o requerimento do Sr. Flores da Cunha, era que solicita o pronunciamento da Câmara em favor do casal Rosenberg, por meio de pedido de clemência a ser dirigido ao presidente Eisenhower. Achando-se o assunto em pauta, falou primeiro o Sr. Samuel Duarte, em nome da Comissão da Justiça que se pronunciou favoravelmente à iniciativa não lhe encontrando qualquer óbice constitucional ou jurídico. (...) Como deputado, [o sr. Artur Santos] subscrevera um telegrama também assinado por outros colegas, com um apelo em favor dos Rosenberg. Mas a Câmara, como órgão legislativo, não poderia fazer a mesma coisa. Assim, apresentou a seguinte emenda ao requerimento do Sr. Flores da Cunha: "ACâmara dos Deputados manifesta a sua confiança em que o presidente da República dos Estados Unidos da América do Norte comute a pena de morte a que foi condenado o casal Rosenberg, certa de que interpreta o pensamento humanitário e cristão do povo brasileiro." ${ }^{37}$ 
Ainda de acordo com Dulles, as seguidas negativas da justiça dos EUA aos diversos recursos a ela dirigidos pelo advogado do casal levavam a crer na motivação política do processo. As próprias notícias publicadas no "Correio da Manhã" e na "Tribuna da Imprensa", creditadas a agências internacionais de notícias, por essa época, mostravam-se embebidas do tom emocional em torno do caso e do provável drama vivido pelo casal, apresentando o apelo de intelectuais, como Einstein, e do Papa Pio XII em favor da clemência. ${ }^{38}$

A intervenção do Papa Pio XII, em favor dos esposos Rosenberg, condenados à morte nos Estados Unidos, não se efetuou oficialmente. (...) o Santo Padre interveio em favor dos condenados à morte - como aliás fez outras vezes, tratando-se de salvar vidas humanas, e isto - como diz o "Osservatore Romano" - "em virtude das razões superiores de caridade, que são próprias ao seu Ministério Apostólico."’39

Após o silenciamento da USIA, nos referidos jornais, em relação ao processo, no período de fevereiro a junho, enquanto perdurou a dúvida entre os serviços de inteligência do governo estadunidense quanto à melhor maneira de proceder em relação aos Rosenberg, a agência voltou a tratar do "mais sério caso de espionagem da história dos Estados Unidos", conforme entendimento dos funcionários do Departamento de Justiça. Haviam se passado alguns dias da execução de Julius e Ethel, em junho, e a agência de informação e propaganda veiculou uma última e longa matéria no "Correio da Manhã" sobre os "espiões atômicos", intitulada "Histórico do caso Rosenberg". A matéria fazia, como indicara a coordenação do Secretário Dulles, uma análise histórica e factual do processo, demonstrando, em resumo, o respeito à constitucionalidade democrática e ao ideal de justiça do mundo livre que exigiam, todavia, normas rígidas àqueles que atentassem contra elas.

Os Rosenbergs foram condenados à morte em 5 de abril de 1951, por crime de espionagem - entrega de segredos atômicos dos Estados Unidos a uma potência estrangeira. Todos os tribunais recusaram modificar a sentença, sob a alegação de que as provas apresentadas no julgamento de março de 1951 não deixaram dúvida quanto à culpabilidade. O caso Rosenberg vem sendo motivo de intensa campanha de propaganda comunista, desde a prisão do casal, em julho de 1950. (...) O júri deu o veredito em 29 de março de 1951, e a Côrte suspendeu a sessão para 5 de abril, para a sentença. (...) No dia seguinte ao da sentença contra os Rosenbergs, 6 de abril, os advogados da defesa apelaram para novo julgamento, o primeiro dos muitos passos concedidos ao casal pela justiça norte-americana. (...). 
Desde a condenação dos Rosenbergs, as acusações de que aos mesmos fora negado um julgamento leal e imparcial vem sendo refutadas pela imprensa norte-americana, por líderes religiosos e por diversas organizações nacionais. A União Americana de Liberdades Civis disse que na sentença de morte imposta aos Rosenbergs não havia a menor violação das liberdades civis. (...) $\mathrm{O}$ "Christian Science Monitor" disse em editorial que os Rosenbergs tiveram julgamento imparcial e que a decisão acerca dos seus apelos de clemência devia ser tomada levando em consideração "os verdadeiros interesses da civilização, a qual os Rosenbergs, durante anos, tentaram destruir". ${ }^{40}$

O Escritório Federal de Investigação (FBI) chegara a Julius e Ethel, em julho e agosto de 1950, respectivamente, somente após sucessivas prisões, desde a Inglaterra, de espiões soviéticos infiltrados no projeto de desenvolvimento da bomba atômica, em Los Alamos. Karl Fuchs, Harry Gold, David Greenglass, este irmão de Ethel, todos tiveram penas relativamente brandas, se comparadas à do casal Rosenberg, ao confirmarem histórias e delatarem outros agentes soviéticos ao FBI. ${ }^{41}$ Julius e Ethel se negaram a ajudar o Departamento de Justiça e o Bureau e se viram lançados ao público como evidências privilegiadas do embate pela opinião pública no cenário de Guerra Fria - e, como vimos, mais do que isso, ao a partir deles se tentar cindir o movimento comunista no mundo em torno da questão judaica. O casal, afinal, sonhava não tanto com a identidade judaica, se não com a vitória soviética na Guerra Fria. À identidade com Roger Casement, manitiveram-se dignos de seu sonho.

\section{Notas}

1 LLOSA, Mario Vargas. O sonho do Celta. (trad. Paulina Wacht e Ari Roitman). Rio de Janeiro: Objetiva, 2011, p. 27.

2 Por muitos anos, o governo da Inglaterra negou que os supostos Diários de Casement passassem por um exame científico independente. Em 2002, quando o permitiu, a controvérsia sobre a autenticidade dos Black Diaries não se encerrou. Conferir: TILZEY, Paul. Roger Casement: Secrets of the Black Diaries. Disponível em: $<$ http://www.bbc.co.uk/history/british/britain wwone/casement 01.shtml > . Acesso em: 12/10/2016.

3 COSTIGAN, Giovanni. The Treason of Sir Roger Casement. In: The American Historical Review. Bloomington: Oxford University Press. vol. 60, n. 2, Jan., 1955, p. 283-302; SHAW, George Bernard. The Roger Casement Trial. The Massachusetts Review. Amherst: University of Massachusetts. vol. 5, no. 2, Winter, 1964, p. 311-314; ANDERS, Roger. The Rosenberg Case Revisited: The Greenglass Testimony and the Protection of Atomic Secrets. The American Historical Review. Bloomington: Oxford University Press, Vol. 83, n. 2, Apr., 1978.

4 Adotamos, genericamente, "opinião pública" como expressão da posição hegemônica de uma população sobre um determinado tema. Para uma leitura do debate acerca da expressão, 
cf.: CHILDS, Harwood L. Que é opinião pública. In: CHILDS, Harwood L. Relações públicas, propaganda e opinião pública. 2a . ed. Rio de Janeiro: FGV, 1967. p. 44-61.

5 Fundado em 15 de junho de 1901, por Edmundo Bittencourt, e extinto em 8 de julho de 1974, o jornal foi durante grande parte de sua existência um dos principais órgãos da imprensa brasileira, destacando-se como um sofisticado "jornal de opinião" e de posição nitidamente anticomunista. Para mais detalhes ver: Verbete Temático - Correio da Manhã em Dicionário Histórico-Biográfico Brasileiro (FGV/CPDOC).

6 Fundado por Carlos Lacerda em 27 de dezembro de 1949, o jornal representava as principais propostas da União Democrática Nacional (UDN), pela qual Lacerda seria eleito governador do estado da Guanabara, em 1960; era, ademais, um dos principais órgãos de caráter anticomunista e de oposição às remanescentes forças políticas vinculadas a Getúlio Vargas. Para mais detalhes ver: Verbete Temático - Tribuna da Imprensa em Dicionário Histórico-Biográfico Brasileiro (FGV/CPDOC).

7 O PROCESSO DOS ESPIÕES ROSENBERG. Correio da Manhã. Rio de Janeiro, 1/1/1953, caderno 2, p. 1 .

8 A United States Information Agency possuía, no estrangeiro, postos avançados, os USIS, que contavam com salas de exibição de filmes, conferências, seminários, espaços para exposição artísticas, cursos de inglês, da história e da cultura estadunidense, biblioteca e responsabilizava-se, ainda, pela veiculação de material de propaganda nos serviços de mídia brasileiros, como os citados jornais cariocas. Para um estudo geral da USIA, conferir: CULL, Nicholas J. The Cold War and the United States Information Agency: American Propaganda and Public Diplomacy, 1945-1989. Cambridge Studies in the History of Mass Communication. Cambridge University Press, 2008.

9 O Conselho era composto pelos principais membros dos órgãos da estrutura de Estado dos EUA e seu trabalho era, grosso modo, compor as diretrizes da política externa do país. POWERS, Richard Gid. Not Without Honor: the History of American Anticommunism. Yale, Yale University Press, 1998.

10 O responsável pela campanha contrária à execução de Sacco e Vanzetti foi Willi Münzenberg, o gestor das campanhas de propaganda cultural mobilizadas pelo Kremlin antes da Segunda Guerra Mundial. Ajudados pela campanha de Münzenberg, em pouco tempo, surgiram protestos no interior dos Estados Unidos e em diversas outras partes do mundo, sobretudo na Europa. Apesar dos diversos apelos, pedidos de clemência, inclusive do Papa Pio IX, e da considerável comoção mundial, Sacco e Vanzetti foram executados a 23 de agosto de 1927. Conferir: KOCH, Stephen. Double lives: Stalin, Willi Münzenberg and the seduction of the intellectuals. New York: Enigma Books, 2004.

11 Os programas de propaganda cultural elaborados e conduzidos pelos governos da União Soviética e dos Estados Unidos da América têm se constituído como um outro campo de investigação, especialmente pela historiografia estadunidense, o qual se tem chamado de Guerra Fria Cultura (Cultural Cold War). O alcance e significado de tais políticas, especialmente no que concernem à América Latina e ao Brasil, parecem ainda longe de se esgotarem. A respeito do tema, destaco os seguintes trabalhos: CANCELLI, Elizabeth . O Brasil e os outros: o poder das ideias. Porto Alegre: EDIPUCRS, 2011; GRÉMION, Pierre. Intelligence de l'anticommunisme: Le Congrès pour la liberté de la culture à Paris (1950-1975). Paris: Fayard, 1995; SAUNDERS, Frances Stonor. Quem Pagou a Conta?. (trad. Vera Ribeiro). Rio de Janeiro: Record, 2008.

12 Cf: University of Wisconsin Digital Collection - Foreign Relations of the United States series. United States Department of State. Slany, William Z., (Editor). Foreign relations of the United States, 1952-1954. National security affairs (in two parts). Volume II, Part 2. U.S. 
Government Printing Office, 1952-1954. Memorandum by the Deputy Assistant Secretary of State for Public Affairs (Phillips) to the Under Secretary of State (Bruce), December 11, 1952, p. 1640-1641; PROTESTA INOCÊNCIA O CASAL ROSENBERG. Correio da Manhã, Rio de Janeiro, 6/1/1953, caderno 1, p. 1. e COOK, Blanche Wiesen. The Rosenbergs and the Crimes of a Century. In: GARBER, Marjorie \& WALKOWITZ, Rebecca. Secret Agents: the Rosenberg case, McCarthyism, and fifties America. Routledge: New York \& London, 1995.

13 University of Wisconsin Digital Collection - Foreign Relations of the United States series. United States Department of State. Slany, William Z., Editor. Foreign relations of the United States, 1952-1954. National security affairs (in two parts). Volume II, Part 2. U.S. Government Printing Office, 1952-1954. The Secretary of State to certain Diplomatic Posts. June 13, 1953, p. 1711-1713.

14 Sobre o caso Igor Gouzenko, conferir: KNIGHT, Amy. Como começou a Guerra Fria: o caso Igor Gouzenko e a caçada aos espiões soviéticos. (trad. Carlos Duarte e Ana Duarte). Rio de Janeiro: Record, 2008.

15 University of Wisconsin Digital Collection - Foreign Relations of the United States series. United States Department of State. Slany, William Z., Editor. Foreign relations of the United States, 1952-1954. National security affairs (in two parts). Volume II, Part 2. U.S. Government Printing Office, 1952-1954. Memorandum by the Deputy Assistant Secretary of State for Public Affairs (Phillips) to the Under Secretary of State (Bruce), December 11, 1952, p. $1640-1641$.

16 LUKES, Igor. The Rudolf Slansky Affair: New Evidence. Slavic Review. Champaign: University of Illinois. vol. 58, $\mathrm{n}^{\circ}$. 1, Spring, 1999. O texto do historiador Igor Lukes traz, em nota de rodapé, a informação de que Spencer M. King, da embaixada dos Estados Unidos, em Praga, julgava que a única explicação razoável para tal reação dos acusados seria o uso de drogas, ou, mais provavelmente, a tortura psicológica e física.

17 Idem, 1999 e SOARES, Luiz Carlos. O pós-1945: os complexos bélico-militares e a guerra fria. In: SOARES, Luiz Carlos; SILVA, Francisco Carlos Teixeira. Reflexões sobre a Guerra. Rio de Janeiro: 7Letras; FAPERJ, 2010.

18 DECLARAÇÃO DE GUERRA: COMO OS JUDEUS RECEBERAM O COMUNICADO RUSSO. Tribuna da Imprensa, Rio de Janeiro, 14/1/1953, caderno 1, p. 2.

19 University of Wisconsin Digital Collection - Foreign Relations of the United States series, United States Department of State. Slany, William Z., Editor. Foreign relations of the United States, 1952-1954. Eastern Europe; Soviet Union; Eastern Mediterranean. Volume VIII. U.S. Government Printing Office, 1952-1954, The Secretary of State to the Embassy in the Soviet Union. Washington, January 26, 1953, p. 1073-1074.

20 ARENDT, Hannah. Origens do totalitarismo (trad. Roberto Raposo). São Paulo: Companhia das Letras, 1989, p. 352

21 Idem., 1989, p. 339-354.

22 Lênin, em 1903, já havia assinalado que o nacionalismo judeu era manifestadamente reacionário e conflitante com os interesses do proletariado judaico, posição que Stálin, dez anos depois, seguia num panfleto intitulado Marxismo e a Questão Nacional. Cf: KRAMMER, Arnold. [Untitled]. Russian Review. Lawrence: University of Kansas. vol. 40, $\mathrm{n}^{\circ} .2$, Apr., 1981.

23 Além do trabalho citado de Hannah Arendt, cf.: GITELMAN, Zvi e RO’I, Yaacov (Ed.). Revolution, repression, and revival: the Soviet Jewish Experience. The Rowman e Littlefield Publishing Group., United Kingdom, 2007, p. 179 e ss. 
24 A CIO CONDENA O ANTI-SEMITISMO RUSSO. Correio da Manhã, Rio de Janeiro, 15/02/1953, caderno 1, p. 10; e INTENSIFICA-SE CAMPANHA ANTI-SEMITA NA RÚSSIA E SATÉLITES. Correio da Manhã., Rio de Janeiro, 23/01/1953, caderno 1, p. 9. Outro exemplo de notícia veiculada pela USIA é: CONTINUAM OS EXPURGOS NOS PAÍSES SATÉLITES DA RÚSSIA. Correio da Manhã, Rio de Janeiro, 26/07/1953.

25 A partir da vivência do trabalho nos postos do United States Information Services e de relatórios de avaliação das atividades executadas pela USIA, a agência passou, a partir de uma resolução de outubro de 1953 do Conselho de Segurança Nacional (NSC 165/1), a distribuir aos jornais material de propaganda sem atribuição, isto é, que não possuíam crédito de alguma agência de notícias. $O$ entendimento dos serviços de inteligência do governo estadunidense era de que, atuando dessa maneira, o público aceitaria melhor o material de propaganda da agência.

26 CAMPANHA ANTI-SEMITA NA CORTINA DE FERRO. Tribuna da Imprensa, Rio de Janeiro, 16/1/1953, caderno 1, p.7. Outras notícias sobre o antissemitismo na URSS que apareceram na Tribuna, mas veiculadas por agências internacionais de notícias são: AUMENTANDO O EXPURGO: MAIS PRISÕES NA ALEMANHA ORIENTAL. Tribuna $d a$ Imprensa, Rio de Janeiro, 16/1/1953, caderno 1, p. 2.; JUDEUS NO SETOR RUSSO. Tribuna da Imprensa, Rio de Janeiro, 24-25/1/1953, caderno 1, p. 5.

27 Do original em inglês: "The couple is ideally situated to serve as leading instruments of a psychological warfare campaign designed to split world communism on the Jewish issue, to create disaffected groups within the membership of the Parties, to utilize these groups for further infiltration and for intelligence work." COOK, Blanche Wiesen. The Rosenbergs and the Crimes of a Century. In: GARBER, Marjorie \& WALKOWITZ, Rebecca L. Secret Agents. Op. Cit., p. 25.

28 Do original em inglês: "appeal to Jews in all countries to get out of the communist movement and seek to destroy it." Idem.

29 HAYNES, John E. Red Scare or Red Menace?: American communism and anticommunism in the cold war era. Chicago: Ivan R. Dee, 1996, p. 69-70; University of Wisconsin Digital Collection - Foreign Relations of the United States series. United States Department of State. Slany, William Z., Editor. Foreign relations of the United States, 1952-1954. National security affairs (in two parts). Volume II, Part 2. U.S. Government Printing Office, 1952-1954. Memorandum by the Deputy Assistant Secretary of State for Public Affairs (Phillips) to the Under Secretary of State (Bruce), December 11, 1952, p. 1640-1641.

30 Idem. No caso Rosenberg, essa diretriz parece ter sido adotada, conforme a notícia da USIA a seguir, em relação também ao público estadunidense, prática que havia sido vetada à agência em sua fundação.

31 NÃO HOUVE VIOLAÇÃO DAS LIBERDADES CIVIS NO CASO ROSENBERG. Correio da Manhã. Rio de Janeiro, 10/2/1953, caderno 1, p. 10. Ver também: O PROCESSO DOS ESPIÕES ROSENBERG. Correio da Manhã, Rio de Janeiro, 1/1/1953, caderno 2, p. 1.

32 University of Wisconsin Digital Collection - Foreign Relations of the United States series. United States Department of State. Slany, William Z., Editor. Foreign relations of the United States, 1952-1954. National security affairs (in two parts). Volume II, Part 2. U.S. Government Printing Office, 1952-1954. The Secretary of State to certain diplomatic posts, February 11,1953 , p. 1668-1670.

33 O PROCESSO DOS ESPIÕES ROSENBERG. Correio da Manhã, Op. Cit. Exemplos de notícias publicadas por agências internacionais de notícias acompanhando o argumento do juiz do processo do casal Rosenberg são: NEGADO O APELO AO CASAL ROSEMBERG. Correio da Manhã, Rio de Janeiro, 3/1/1953, caderno 1, p. 11.; e SÓ TRUMAN PODERÁ 
SALVAR OS ESPIÕES ROSEMBERG DA CADEIRA ELÉTRICA. Correio da Manhã, Rio de Janeiro, 4/1/1953, caderno 4, p. ?.

34 A captura e o processo de Ethel parecia, nesse sentido, uma maneira de o Departamento de Justiça pressionar Julius a delatar seus contatos, permitindo o desmantelamento da rede de espionagem soviética nos EUA, uma vez que nada havia contra a esposa de Julius a não ser o testemunho de seu irmão, David Greenglass. Quando de sua prisão, Greenglass afirmou que sua irmã, Ethel, não tinha relação com a espionagem soviética, mas, depois, mudou seu testemunho afirmando que a irmã documentava as informações coletadas por Julius. Décadas depois, David Greenglass afirmou que Ethel, de fato, não tinha qualquer participação com a URSS. Quem, de fato, documentava informações a respeito da bomba era sua própria esposa Ruth, que o recrutara para servir como espião. David implicara sua irmã em função de que, em troca de seu testemunho, sua esposa Ruth ficaria em liberdade e poderia cuidar dos dois filhos. Cf: ROBERTS, Sam. The Brother: The Untold Story of the Rosenberg Case. New York: Simon \& Schuster Paperbacks, 2011. Sobre a ideia do Departamento de Justiça de que Julius era uma figura importante na espionagem soviética, ver: ANDERS, Roger. The Rosenberg Case Revisited: The Greenglass Testimony and the Protection of Atomic Secrets. The American Historical Review. Bloomington: Oxford University Press. vol. 83, nº. 2, Apr., 1978.

35 Os jornais "Correio da Manhã" e "Tribuna da Imprensa", em material veiculado por agências internacionais de notícias, como a Reuters e a United Press, noticiaram sistematicamente os adiamentos do processo. Cf: ADIADA A EXECUÇÃO DOS ESPIÕES ROSENBERGS. Correio da Manhã, Rio de Janeiro, 18/06/1953, caderno 1, p. 1. Outras notícias publicadas pelo "Correio da Manhã" a esse respeito são: OS ROSENBERG SERIAM PERDOADOS. Correio da Manhã, Rio de Janeiro, 24/05/1953, caderno 1, p.1; Acrescente-se o fato de que o próprio presidente Harry Truman parece ter optado por postergar a decisão sobre o caso até sua saída da presidência. Cf: TRUMAN APROVEITARÁ OS ROSENERG PARA SUA GRANDE SAÍDA. Correio da Manhã, Rio de Janeiro, 15/1/1953, caderno 1, p. 5; e TRUMAN E OS ROSENBERG. Tribuna da Imprensa, Rio de Janeiro, 16/1/1953, caderno 1, p. 2.

36 SAUNDERS, Frances Stonor. Op. Cit., p. 199 e ss.

37 DISCUTE-SE NA CÂMARA PEDIDO DE CLEMÊNCIA PARA O CASAL ROSENBERG. Correio da Manhã, Rio de Janeiro, 18/06/1953, caderno 1, p. 9.

38 University of Wisconsin Digital Collection - Foreign Relations of the United States series. United States Department of State. Slany, William Z., Editor. Foreign relations of the United States, 1952-1954. National security affairs (in two parts). Volume II, Part 2. U.S. Government Printing Office, 1952-1954. The Secretary of State to certain diplomatic posts, February 11, 1953, p. 1668-1670.; EINSTEIN A FAVOR DOS ROSENBERG. Correio da Manhã, Rio de Janeiro, 14/1/1953, caderno 1, p. 1; e DISCUTE-SE NA CÂMARA PEDIDO DE CLEMÊNCIA PARA O CASAL ROSENBERG. Correio da Manhã, Rio de Janeiro, 18/06/1953, caderno 1, p. 9.

39 PIO XII PEDE CLEMÊNCIA PARA O CASAL ROSEMBERG. Tribuna da Imprensa, Rio de Janeiro, 14-15/2/1953, caderno 1, p. 5.

40 HISTÓRICO DO CASO ROSENBERG. Correio da Manhã, Rio de Janeiro, 25/6/1953, caderno 2, p. 3.

41 KNIGHT, Amy. Op. Cit.

Recebido em 14/10/2017

Aprovado em 06/12/2016 